\title{
Some Translations in Vascular Neurology
}

\section{The Johann Jacob Wepfer Award 2008}

Marie-Germaine Bousser

Hôpital Lariboisière AP-HP, Université Paris Diderot, Paris, France

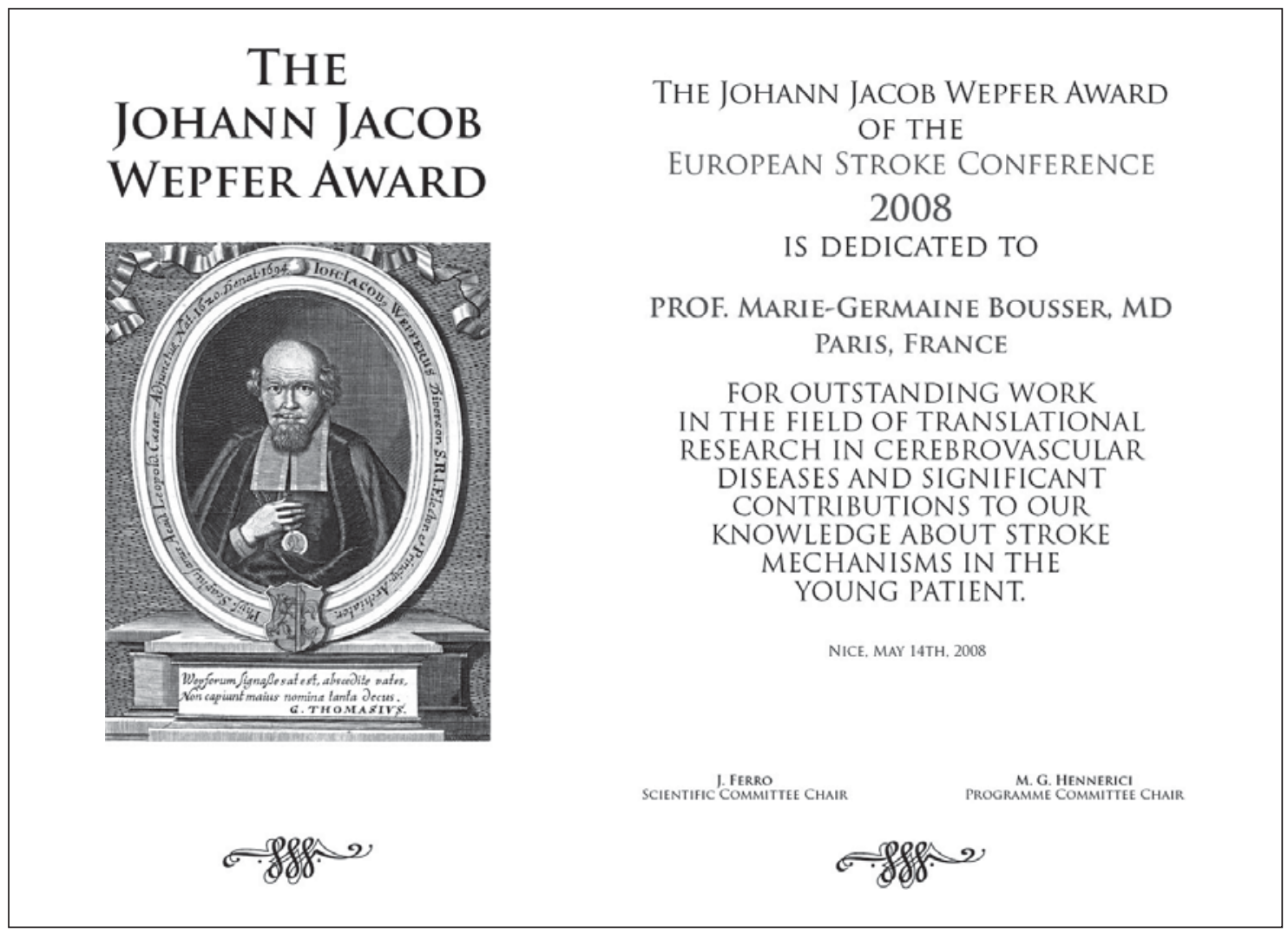

The Johann Jacob Wepfer Award 2008 was presented by J.L. Mas (Paris) and M.G. Hennerici (Mannheim) to M.-G. Bousser (Paris). J. van Gijn (Utrecht) introduced the Award Lecture.

\section{KARGER}

Fax +41613061234 E-Mail karger@karger.ch www.karger.com
Marie-Germaine Bousser

Hôpital Lariboisière Service de Neurologie

2, rue Ambroise Paré

FR-75012 Paris (France)

Tel. +33 1499525 97, Fax +33 1499525 96, E-Mail mg.bousser@lrb.aphp.fr 


\section{Key Words}

Translational research • Aspirin · CADASIL •

Hemicraniectomy $\cdot$ Patent foramen ovale $\cdot$ Migraine
I have thus selected 4 translations: (1) from men to women; (2) from bedside to bench; (3) from research to practice, and (4) from case reports to multidisciplinary randomized clinical trials.

\begin{abstract}
'Translation' in medicine immediately suggests 'translational research', but there are many other varieties of 'translation'. I have selected 4 translations in the field of vascular neurology in which I have been involved in different respects: (1) the translation of results from men to women, taking the example of aspirin which, in primary prevention, decreases the risk of myocardial infarction in men and the risk of cerebral infarction in women, the reason for this sex difference being so far unknown; (2) the 'inverse translational research', from bedside to bench, taking the example of the disease we have identified - CADASIL - and showing how the study of one patient and his family led to the identification of a gene, Notch3, so far unknown in humans and to the discovery of its key role in the physiology of vascular smooth muscle cells; (3) the translation from individual case reports to multidisciplinary trials taking the example of hemicraniectomy in malignant cerebral infarction and emphasizing the interest in such rare and severe conditions of pooling and reporting the results of randomized clinical trials before the results of individual trials, and (4) the translation from research to practice, emphasizing not the well-known 'evidence to practice gap' but the slippery slope of 'lack of evidence to overpractice', taking the example of patent foramen ovale closure in migraine.

Copyright $\odot 2008$ S. Karger AG, Basel
\end{abstract}

'Some translations in vascular neurology'. This is a rather vague title and the word 'translation' immediately suggests translational research. Of course, translational research is an enterprise as crucial in vascular neurology as in all other areas of medicine but I will not talk about translational research: it has its own funding, its scientific societies and foundations, its specific journals, and, as you will see later, it also has different meanings for different people [1].

I would like to share with you some of the many interesting translations I, as a clinician involved in research, came across over the years, in vascular neurology. I could have chosen some very well-known translations such as translations from animal results to humans, from phase 2 trials to phase 3 , but with the recent failure of a number of these phase 3 trials in the acute treatment of stroke, it would have been too depressing.

Some Translations in Vascular Neurology

\section{Translations of Results from Men to Women}

Much has been written about gender differences in stroke: differences in incidence, prevalence, awareness, etiologies, recovery, and care [2-5], but one of the most intriguing example of the hazardous translation of results from men to women is the 'sex story' of aspirin.

The fascinating story of aspirin goes back to the use of willow leaves and barks by the Sumerians, Egyptians, and Greeks, then through the Middle Ages up to the synthesis of acetylsalicylic acid in 1897 by Felix Hoffmann [6]. Aspirin was a wonder drug for half a century and in 1950, it earned a place in the Guinness Book of Records as the most popular painkiller in the world. However, aspirin nearly disappeared in the sixties when the first nonmorphinic analgesic (acetaminophen) in 1956 and the first nonsteroidal anti-inflammatory drug (ibuprofen) in 1962 appeared. The death of aspirin seemed unavoidable particularly since it was shown to induce gastrointestinal bleeding [7] and to be responsible for a childhood encephalopathy [8] now known as Reye's syndrome.

Yet as early as 1956, an American general practitioner had reported the strange observation that 'Not a single case of detectable coronary or cerebral thrombosis occurred among some 8,000 patients who faithfully adhered to this regimen ( 1 or 2 aspirin a day) during a period of 8 years' [9]. It was later shown that aspirin was able to inhibit platelet aggregation $[10,11]$, but the real renaissance of aspirin occurred in 1971 with the landmark discovery by John Vane that the mechanism of action of aspirin was the inhibition of prostaglandin synthesis [12]. That very same year, Harrison et al. [13] in Queen Square reported 2 patients who had repeated episodes of amaurosis fugax which disappeared while on aspirin but reappeared a few days after aspirin cessation when the patient was given a placebo. The authors rightly concluded that it was now crucial to start large randomized clinical trials to test the efficacy of aspirin in the secondary prevention of amaurosis fugax and of cerebral ischemic events. At the same time, I was myself finishing my thesis on experimental arterial thrombosis and I was able to show that aspirin completely inhibited platelet emboli in the small cortical arteries of the rabbit [14].

Cerebrovasc Dis 2008;26:328-334 
The stage was set for randomized clinical trials and the first two randomized controlled trials devoted to aspirin in the secondary stroke prevention were performed in North America, the first one by Fields et al. $[15,16]$ and the second one by the Canadian Cooperative Study Group [17], which was the first to raise the question of aspirin and sex. The Canadian randomized trial of aspirin and sulfinpyrazone in threatened stroke showed a $31 \%$ reduction of stroke or death, but this benefit was observed only in men in whom the reduction was as high as $48 \%$. By contrast, there was no significant trend in women. The next study was our French AICLA study which showed a $45 \%$ relative reduction of stroke risk with aspirin and aspirin-dipyridamole [18]. It also showed a significant decrease in the risk of myocardial infarction, which was a new finding at that time and it did not show any sex difference. We therefore concluded by contrast to the Canadian group that aspirin was also effective in women. This led to a long debate between Henry Barnett, the principal investigator of the Canadian trial, and myself which went on for years, Henry Barnett claiming 'aspirin works only in men', and I replying, 'no, it also works in women'. Henry Barnett always used to close this debate by saying: 'I always knew that French women were different!'

After these early studies which were devoted to aspirin in secondary stroke prevention came the first large studies of aspirin in primary prevention: the British and American physician studies which - it is now hard to believe - included only men and which showed a $40 \%$ risk reduction of myocardial infarction, but no prevention of stroke $[19,20]$. Yet, there were still no data about aspirin in primary cardiovascular prevention in women. However, the first antiplatelet trialists' collaboration metaanalysis seemed to close the debate about sex difference in aspirin efficacy when it showed a similar reduction of vascular events in high-risk male and female patients a few years later and the conclusion was that 'women seemed to derive as much benefit as men' [21]. It should be noted that a similar efficacy in high-risk patients was mostly observed in secondary prevention. One had to wait until 2005 to have the first large trial of aspirin in primary prevention of stroke in women: the Women's Health Study [22] which included 39,876 women over 45 years followed for 10 years. This study again raised the question of sex and aspirin showing that in contrast to men, low-dose aspirin (100 mg on alternate days) did not prevent myocardial infarction but significantly decreased stroke rate, with a $24 \%$ decrease in ischemic stroke. This divergent effect of aspirin in men and women is also illustrated in the meta-analysis [22] of 6 primary prevention trials which showed a $32 \%$ risk reduction of myocardial infarction in men, but none in women, and a $19 \%$ risk reduction of stroke in women, but none or even a slightly increased relative risk $(1.13$, range $=0.96-1.33)$ in men. These findings were confirmed in another meta-analysis [23] which showed a significant reduction (12\%) of cardiovascular events in women mostly due to a $17 \%$ reduction of stroke $(\mathrm{OR}=0.83$, range $=0.70-0.97)$, and a $14 \%$ global reduction in men mostly due to a $32 \%$ reduction of myocardial infarction $(\mathrm{OR}=0.68$, range $=0.54-0.86)$. Interestingly, aspirin significantly increased the risk of bleeding to a similar degree among women $(\mathrm{OR}=1.68$, range $=1.13-2.52)$ and men $(\mathrm{OR}=1.79$, range $=1.35-2.20)$.

Why should aspirin be good for the heart of men and for the brain of women? Much has been written about this 'puzzle of aspirin and sex' [24] but so far no good explanation has been found. It does not seem to be due to a different action on cyclooxygenase (COX) since it has been shown that aspirin induces the same inhibition of COX-1 in men and women [25]. It might be partly related to the sex difference in the relative frequencies of myocardial infarction and stroke as illustrated in the placebo group of the 2 large American trials [20, 22]: stroke was much more frequent $(34 / 100,000 /$ year) than myocardial infarction $(97 / 100,000 /$ year) in women, whereas myocardial infarction was far more frequent (439.7) than stroke (179.4) in men, the 2 populations being of similar age [24]. Other potential factors include differences in vascular anatomy, such as smaller coronary arteries in women [26], in the distribution of carotid atheroma [27], in vascular reactivity [28] or in the lowest effective dose of aspirin. Is there a huge overlooked bias underlying this puzzle? Nobody knows. The aspirin saga continues, but the 'sex story' of aspirin in cardiovascular prevention is one of the best examples that 'clinical research must always be organised to account for the biologic and environmental differences between men and women' [24].

\section{Reverse Translational Research}

Translational research, at least what the translational research specialists call the 'T1 translational research', usually refers to the bench-to-bedside enterprise of using knowledge from basic sciences to produce new drugs, new devices or new treatment options for patients [1]. But the interface between basic sciences and clinical medicine can also go in the opposite direction, from bedside to bench, and clinical observations can also lead to prog- 
resses in basic sciences. I will illustrate this with the example of CADASIL (cerebral autosomal dominant arteriopathy with subcortical infarcts and leukoencephalopathy), the acronym we suggested in 1993, when our geneticist co-worker E. Tournier-Lasserve located the responsible gene on chromosome 19 [29].

I will try to make this 30 -year story very short: in 1976, I met a 50-year-old man who had a typical lacunar infarct and leukoencephalopathy on the CT scan in the absence of any vascular risk factor, in particular in the absence of hypertension. No cause was found after an extensive workup. The tentative diagnosis was Binswanger disease, but this could not be accepted in the absence of hypertension. The patient was actually included in our aspirin trial [23]. A few years later, he had another lacunar infarct and he gradually deteriorated with pseudobulbar palsy and subcortical dementia. He remained bedridden for years and died in 1996, 20 years after his first stroke.

This intriguing case started to clarify when, some years later, I was able to examine his 2 children who were in their thirties and had already had clinical and MRI signs of small subcortical infarcts. The daughter had had a pure motor stroke and the son had had a dysarthric episode which lasted 5 days. The MRI was very similar though less severe than that of their father. It was then obvious that this was a familial disease and with Elisabeth TournierLasserve we embarked on the systematic study of this family. We were able to perform an extensive clinical, MRI and genetic study of 57 adult members of the family. Eleven (6 males, 5 females) had already had symptoms at a mean age of 43 years: subcortical ischemic events in 11; pseudobulbar palsy and dementia in 3; migraine in 4; epilepsy in 1 ; manic depressive syndrome in 1 . We were also able to perform a pathological study of 1 patient [30] which confirmed the white matter rarefaction with small deep infarcts and also showed an intracerebral hemorrhage which was the cause of death. The cortex was essentially normal and there was no large artery territorial infarct. These ischemic changes were accompanied by a specific arteriopathy affecting mainly the small perforating and leptomeningeal arteries and characterized by thickened media, abnormal smooth muscle cells and granular osmiophilic material on ultrastructural analysis.

It was in this single family that the location of the responsible gene on chromosome 19 was found by Elisabeth Tournier-Lasserve in 1993 and 3 years later, in 1996, we had gathered 33 families, allowing Anne Joutel, from the genetics team, to identify the responsible gene: Notch3 [31]. Today, in 2008, over 80 mutations of this gene have been reported in some 500 CADASIL families worldwide and we have also reported the first sporadic case [32]. But the most fascinating point is that this Notch3 gene was totally unknown in humans. It was only known in drosophila in which it plays a role in the shape of the wings and in the development of the brain. Nobody knew that it was playing any role in humans, and yet CADASIL shows that it is responsible for a small-artery disease of the brain in human adults. We had indeed gone from bedside to bench [33].

To elucidate what was going wrong in the arteries, Anne Joutel developed a transgenic mouse model carrying one of the most common CADASIL mutations: Arg 90 cys which showed an age-dependent alteration of smooth muscle cells with granular osmiophilic material and Notch 3 ectodomain accumulationsleading to smooth muscle cell degeneration and thickened rigid arteries [34, 35]. Physiological studies performed in these transgenic mice revealed an impaired cerebral vasoreactivity with an increase in myogenic tone and a decrease in flow-induced dilation, thus leading to a permanent increase in the vascular tone of small arteries, which are like 'rigid pipes' $[36,37]$.

These findings in CADASIL and transgenic mice suggested for the first time that Notch3 was a key player in the vascular smooth muscle cell physiology. This was confirmed by studies of Notch3 knockout mice which, although viable and fertile, exhibit prominent defects in small brain arteries soon after birth that are dilated with a thin wall, almost looking like veins. These arteries dilate far too much with a huge increase in cerebral blood flow after angiotensin administration. These data clearly indicate that Notch3 is required for the integrity of small arteries and is a key regulator of myogenic tone and cerebral blood flow autoregulation. Furthermore, it has also been shown that Notch3 plays a key role in the arterial differentiation of smooth muscle cells, and that the arterial identity of smooth muscle cells is specified independently from that of endothelial cells $[38,39]$.

Thus, the study of 1 patient and his family led our group through reverse translational research and thanks to a fantastic collaboration between clinicians and basic scientists to the identification of Notch 3 in humans and to the finding that Notch3 plays a crucial role in the physiology of small arteries. Now comes the classic translational research from bench to bedside in which several groups are involved [40-45], which has already helped us to better understand the clinical manifestations of CADASIL, particularly infarcts and dementia, but has unfortunately not yet led to the emergence of a treatment. A first international randomized placebo-controlled study 
has recently been performed in CADASIL patients with cognitive impairment which showed that donepezil had no effect on the cognitive subscale of the Vascular-Alzheimer's Disease Assessment Scale at 18 weeks but improved several measures of executive function [46]. This first study shows that, some 15 years after the study of our first single family, it is now possible to perform a large international randomized clinical trial devoted to CADASIL.

\section{From Individual Case Reports to Multidisciplinary Trials}

My third translation will be much shorter; it is the well-known translation from individual case reports to large multidisciplinary trials. There are a number of excellent examples of such transition in vascular neurology including those of aspirin, carotid surgery and stenting, aneurysm surgery and coiling, or thrombolysis, but I have chosen the example of hemicraniectomy in malignant middle cerebral artery infarction, which is one of the oldest neurosurgical procedures, i.e. the removal of a segment of the cranial vault to decrease intracranial pressure and prevent death from herniation. Three such patients were reported in 1981 illustrating right away the crucial dilemma of this surgery: the 3 patients survived but 2 were left with a severe deficit [47]. Many case reports and small series followed [48-50] until two landmark papers by W. Hacke's team in Heidelberg. The first was about 55 patients with malignant middle cerebral artery infarction of whom $78 \%$ died of herniation [51]. The second showed that of 63 patients who were treated by early hemicraniectomy, $73 \%$ survived and that early surgery reduced the length of critical care treatment [52]. However, there was still a lot of skepticism and a great fear that survivors would remain totally dependent.

Three European groups, in France [53], Germany [54] and the Netherlands [55], independently decided to embark each on a prospective nationwide randomized clinical trial (DECIMAL, DESTINY and HAMLET, respectively), using the modified Rankin scale (mRS) as main outcome criterion. There were some differences in the protocols such as the timing of surgery (from less than $30 \mathrm{~h}$ in the French trial to less than $99 \mathrm{~h}$ in the Dutch trial), the neuroimaging tool required at inclusion (MR diffusion with a volume of $>145 \mathrm{ml}$ in the French trial, CT scan in the 2 others), and the upper age limit ( 55 years in the French trial, 60 years in the 2 others). However, overall, the three trials had many similarities, particularly as regards the main inclusion and outcome criteria. In 2006, the French and German studies had each found a significant effect on mortality but not enough patients to get a result on functional outcome and the recruitment of patients was getting increasingly difficult. Instead of going on for years, we all met and decided: firstly to discontinue our trials, secondly to pool our data before the results of each trial, thirdly to ask an independent group, that of Peter Rothwell in Oxford, to perform the pooled analysis of the three trials, and fourthly to publish the pooled analysis before the individual trials [56]. We thus had a sufficient number of patients, 93, to show not only a dramatic reduction of death, from 76 to $26 \%$, but also a significant benefit in functional outcome, with $43 \%$ of patients with an mRS score of $\leq 3$. Viewed in another way, hemicraniectomy resulted in a $49 \%$ absolute risk reduction of death and an absolute increase in the proportion of patients with an mRS score of 2 (12\%), an mRS score of $3(10 \%)$ and an mRS score of 4 (29\%). Only 2 patients in the surgical group (and 2 in the medical) had an mRS score of 5 . We therefore now have figures that we can share with patients and families to help them make the difficult decision, on a case-by-case basis, to perform hemicraniectomy in malignant middle cerebral artery infarction. This somewhat unconventional strategy of pooling the data and publishing the results of such pooled analysis before the results of individual trials could probably be applied to other rare situations or conditions, thus avoiding a loss of time and money and allowing more rapid answers to difficult questions.

\section{Translation from Research to Practice}

My fourth translation deals with the T2 translational research, translation from research to practice, which is far less recognized and funded than the T1 bench-tobedside translational research. Yet, as emphasized by Steven Woolf in a recent provocative commentary in the Journal of the American Medical Association: 'T2 TR may do more to decrease morbimortality than T1' [1]. The well-known major aim of T2 translational research is to close the evidence-to-practice gaps, but I will not talk about the numerous evidence-to-practice gaps that we face in vascular neurology such as underuse of oral anticoagulants in atrial fibrillation or of blood pressure-lowering drugs in primary and secondary stroke prevention. Such gaps have been emphasized over and over again, but unfortunately they still persist.

I would just like to give one example of another type of translation from research to practice which seems to be rapidly growing: the very slippery slope of 'lack of ev- 
idence to overpractice'. As a migraine and stroke specialist, I have chosen patent foramen ovale (PFO) closure, presented and already used by some interventional cardiologists, as a treatment of migraine. This is based on a bidirectional statistical association between PFO and migraine with aura (MA) - but not migraine without aura - which is as follows [57, 58]:

- in patients with MA, PFO is twice as frequent as in controls;

- in patients with PFO, MA is twice as frequent as in those without PFO;

- attacks were said to disappear after PFO closure but in studies that were all nonrandomized;

- the first double-blind study, MIST, was presented at the 2006 American College of Cardiology meeting as positive [59].

Yet, when MIST was recently published in Circulation [60], it translated into a completely negative study: 147 patients with a so-called resistant MA and a moderate or large $\mathrm{PFO}$ underwent $\mathrm{PFO}$ closure or a sham procedure, followed by 3 months of healing phase with aspirin + clopidogrel and 3 months of analysis phase, during which all efficacy endpoints, the primary (cessation of attacks) as well as all secondary endpoints were negative. As emphasized in the accompanying editorial, 'the de facto retraction of a positive clinical trial previously presented at a high profile international meeting remains a major issue of concern from both the scientific and ethical perspectives' [61]. Despite the negative result, in many coun- tries, there presently is a rush to offer this off-label closure device to migraine sufferers, even to patients with migraine without aura, and there are several ongoing randomized studies on the same topic. Although it is likely that in some patients - probably very few - there is a relationship between MA and PFO, there are no data proving that it is a causal relationship and no scientific evidence to justify PFO closure in migraineurs, even in those with MA $[57,58]$.

Unfortunately, there are other examples in vascular neurology of dangerous jumps from 'lack of evidence to overpractice', but, as emphasized again by Steven Woolf [1], 'Discovering a better way to ensure that patients receive the care they need - safely, compassionately, and when they need it - is not easy and poses formidable methodologic challenges. Spectacular new devices are more fascinating to the public and more lucrative for industry'. I am not saying that we do not need new devices but we want devices of proven, favorable benefit/risk ratio. Trying to find ways of preventing such overpractice is the task not only of researchers in T2 translational research, but of us all, bedside clinicians!

I do hope that I have not lost you in my translations and I would like to finish by thanking most warmly all the coworkers, colleagues, hospital staff, secretaries, nurses, patients and families with whom I have worked in my 3 hospitals in Paris (Salpêtrière, Saint-Antoine and Lariboisière) and without whom I would not be here today to receive this Jacob Wepfer Award.

\section{References}

1 Woolf SH: The meaning of translational research and why it matters. JAMA 2008;299: 211-213.

2 Bousser MG: Stroke in women. Circulation 1999;99:463-467.

3 Bushnell CD: Oestrogen and stroke in women: assessment of risk. Lancet Neurol 2005;4: 74-751.

4 Bushnell CD, Hurn P, Colton C, Miller VM, del Zoppo G, Elkind MSV, et al: Advancing the study of stroke in women. Stroke 2006; 37:2387-2399.

5 Reid JM, Dai D, Gubitz GJ, Kapral MK, Christian C, Phillips SJ: Gender differences in stroke examined in a 10 -year cohort of patients admitted to a Canadian teaching hospital. Stroke 2008;39:1090-1095.

6 Jeffreys D: Aspirin: The Remarkable Story of a Wonder Drug. New York, Bloomsbury, 2005

7 Alvarez AS, Summerskill WHJ: Gastrointestinal haemorrhage and salicylates. Lancet 1958;ii:179-182.
8 Reye RDK, Morgan G, Baral J: Encephalopathy and fatty degeneration of the viscera: a disease entity in child hood. Lancet 1963;ii:749-752

$\checkmark$ Craven LL: Prevention of coronary and cerebral thrombosis. Miss Valley Med J 1956;78: 213-215.

10 Weiss HJ, Alefort LM, Kochwa S: The effect of salicylates on the haemostatic properties of platelets in man. J Clin Invest 1968;47: 2169-2180.

-11 O’Brien JR: Aspirin and platelet aggregation. Lancet 1968;i:204-205.

12 Vane JR: Inhibition of prostaglandin synthesis as a mechanism of action for aspirin-like drugs. Nature 1971;231:232-235.

13 Harrison MJG, Marshall J, Meadows JC Ross Russell RW: Effect of aspirin in amaurosis fugax. Lancet 1971;ii:743-744.

14 Bousser MG: Effects of combined prostaglandin $E_{1}$ and aspirin on experimental arterial thrombosis in rabbits. Biomedicine 1973; 19:90-93.
15 Fields WS, Lemak NA, Frankowski RF, Hardy RJ: Controlled trial of aspirin in cerebral ischemia. Part 1. Stroke 1977;8:301-314.

-16 Fields WS, Lemak NA, Frankowski RF, Hardy RJ: Controlled trial of aspirin in cerebral ischemia. Part 2. Stroke 1978;9:309-319.

17 Canadian Cooperative Study Group: A randomized trial of aspirin and sulfinpyrazone in threatened stroke. N Engl J Med 1978;299: 53-59.

-18 Bousser MG, Eschwege E, Haguenau M, Lefauconnier JM, Thibult N, Touboul D, Touboul JP, et al: 'AICLA' controlled trial of aspirin and dipyridamole in the secondary prevention of atherothrombotic cerebral ischemia. Stroke 1983;14:5-14.

19 Peto R, Gray R, Collins R, Wheatley K, Hennekens $\mathrm{CH}$, Jamrozik $\mathrm{K}$, et al: Randomised trial of prophylactic daily aspirin in British male doctors. BMJ 1988;296:313-316. 
20 Steering Committee of the Physicians' Health Study Research Group: Final report on the aspirin component of the ongoing Physicians' Health Study. N Engl J Med 1989; 321:129-135.

-21 Antiplatelet Trialists' Collaboration: Collaborative overview of randomised trials of antiplatelet therapy. 1. Prevention of death, myocardial infarction and stroke by prolonged antiplatelet therapy in various categories of patients. BMJ 1994;308:81-106.

-22 Ridker PM, Cook NR, Lee IM, Gordon D, Gaziano JM, Manson JE, et al: A randomised trial of low dose aspirin in the primary prevention of cardiovascular disease in women. N Eng J Med 2005;352:1293-1304.

-23 Berger JS, Roncaglioni MC, Avanzini F, Pangrazzi I, Tognoni G, Brown DL: Aspirin for the primary prevention of cardiovascular events in women and men. JAMA 2006;295: 306-313.

24 Levin RI: The puzzle of aspirin and sex. N Engl J Med 2005;352:1366-1368.

25 Becker DM, Segal J, Vaidya D, Yanek LR, Herrera-Galeano JE, Bray PF, et al: Sex differences in platelet reactivity and response to low-dose aspirin therapy. JAMA 2006;295: 1420-1427.

26 Herity NA, Lo S, Lee DP, et al: Effect of a change in gender on coronary arterial size: a longitudinal intravascular ultrasound study in transplanted hearts. J Am Coll Cardiol 2003;41:1539-1546.

27 Schulz UGR, Rothwell PM: Sex differences in carotid bifurcation anatomy and the distribution of atherosclerotic plaque. Stroke 2001;32:1525-1531.

28 Wittstein IS, Thiemann DR, Lima JAC, et al: Neurohumoral features of myocardial stunning due to sudden emotional stress. N Engl J Med 2005;352:539-548.

-29 Tournier-Lasserve E, Joutel A, Melki J, et al: Cerebral autosomal dominant arteriopathy with subcortical infarcts and leukoencephalopathy maps to chromosome19q12. Nat Genet 1993;3:256-259.

-30 Baudrimont M, Dubas F, Joutel A, et al: Autosomal dominant leukoencephalopathy and subcortical ischemic stroke. A clinicopathological study. Stroke 1993;24:122-125.

- 31 Joutel A, Corpechot C, Ducros A, et al: NOTCH3 mutations in CADASIL, a hereditary adult-onset condition causing stroke and dementia. Nature 1996;383:707-710.

- 32 Joutel A, Dodick DD, Parisi JE, et al: De novo mutation in the NOTCH3 gene causing CADASIL. Ann Neurol 2000;47:388-391.

- 33 Bousser MG, Tournier-Lasserve E: Cerebral autosomal dominant arteriolopathy with subcortical infarcts and leukoencephalopathy: from stroke to vessel wall physiology. J Neurol Neurosurg Psychiatry 2001;70:285-287.

34 Ruchoux MM, Domenga V, Brulin P, et al: Transgenic mice expressing mutant NOTCH3 develop vascular alterations characteristic of cerebral autosomal dominant arteriopathy with subcortical infarcts and leukoencephalopathy. Am J Pathol 2003;162: 329-342.
35 Joutel A, Andreux F, Gaulis S, et al: The ectodomain of the NOTCH3 receptor accumulates within the cerebrovasculature of CADASIL patients. J Clin Invest 2000;105: 597-605.

36 Dubroca C, Lacombe P, Domenga V, et al: Impaired vascular mechanotransduction in a transgenic mouse model of CADASIL arteriopathy. Stroke 2005;36:113-117.

37 Lacombe P, Oligo C, Domenga V, et al: Impaired cerebral vasoreactivity in a transgenic mouse model of cerebral autosomal dominant arteriopathy with subcortical infarcts and leukoencephalopathy arteriopathy. Stroke 2005;36:1053-1058

38 Domenga V, Fardoux P, Lacombe P, et al: $\mathrm{NOTCH} 3$ is required for arterial identity and maturation of vascular smooth muscle cells. Genes Dev 2004;18:2730-2735.

39 Krebs LT, Xue Y, Norton CR, et al: Characterisation of NOTCH3 deficient mice: normal embryonic development and absence of genetic interactions with a NOTCH1 mutation. Genesis 2003;37:139-143.

40 Dichgans M, Filippi M, Bruning R, et al: Quantitative MRI in CADASIL: correlation with disability and cognitive performance. Neurology 1999;52:1361-1367.

41 Dichgans M, Holtmannspotter M, Herzog J, et al: Cerebral microbleeds in CADASIL: a gradient-echo magnetic resonance imaging and autopsy study. Stroke 2002;33:67-71.

-42 O'Sullivan M, Jarosz JM, Martin RJ, et al: MRI hyperintensities of the temporal lobe and external capsule in patients with CADASIL. Neurology 2001;56:628-634.

43 Opherk C, Peters N, Herzog J, et al: Long term prognosis and causes of death in CADASIL: a retrospective study in 411 patients. Brain 2004;127:2533-2539.

44 Singhal S, Markus HS: Cerebrovascular reactivity and dynamic autoregulation in nondemented patients with CADASIL (cerebral autosomal dominant arteriopathy with subcortical infarcts and leukoencephalopathy). J Neurol 2005;252:163-167.

45 Van den Boom R, Lesnik Oberstein SA, Ferrari $\mathrm{MD}$, et al: Cerebral autosomal dominant arteriopathy with subcortical infarcts and leukoencephalopathy: MR imaging findings at different ages - 3rd-6th decades. Radiology 2003;229:683-690.

-46 Dichgans M, Markus HS, Salloway S, et al: Donepezil in patients with subcortical vascular cognitive impairment: a randomised double-blind trial in CADASIL. Lancet Neurol 2008;7:310-318.

47 Rengachary SS, Batnitzky S, Morantz RA, Arjunan K, Jeffries B: Hemicraniectomy for acute massive cerebral infarction. Neurosurgery 1981;8:321-328.

48 Kondziolka D, Fazl M: Functional recovery after decompressive craniectomy for cerebral infarction. Neurosurgery 1988;23:143-147.

49 Delashaw JB, Broaddus WC, Kassell NF, Haley EC, Pendleton GA, Vollmer DG, et al: Treatment of right hemispheric cerebral infarction by hemicraniectomy. Stroke 1990 21:874-881.
50 Carter BS, Ogilvy CS, Candia GJ, Rosas HD, Buonanno F: One year outcome after decompressive surgery for massive nondominant hemispheric infarction. Neurosurgery 1997; 40:1168-1176.

51 Hacke W, Schwab S, Horn M, Spranger M, De Georgia M, Von Kummer R: 'Malignant' middle cerebral artery territory infarction: clinical course and prognostic signs. Arch Neurol 1996;53:309-315.

52 Schwab S, Steiner T, Aschoff A, Schwarz S, Steiner HH, Jansen O, et al: Early hemicraniectomy in patients with complete middle cerebral artery infarction. Stroke 1998;29: 1888-1893.

53 Vahedi K, Vicaut E, Mateo J, Kurtz A, Orabi M, Guichard JP: A sequential design, multicenter randomised, controlled trial of early decompressive craniectomy in malignant middle cerebral artery infarction (DECIMAL trial). Stroke 2007;38:2506-2517.

54 Jüttler E, Schwab S, Schmiedek P, Unterberg A, Hennerici M, Woitzik J: Decompressive surgery for the treatment of malignant infarction of the middle cerebral artery (DESTINY) - A randomized, controlled trial. Stroke 2007;38:2518-2525.

-55 Hofmeijer J, Amelink GJ, Algra A, Van Gijn J, Macleod MR, Kappelle LJ, et al, HAMLET investigators: Hemicraniectomy after middle cerebral artery infarction with lifethreatening edema trial (HAMLET). Protocol for a randomised controlled trial of decompressive surgery in space-occupying hemispheric infarction. Trials 2006;7:29.

56 Vahedi K, Hofmeijer J, Juettler E, Vicaut E, George B, Algra A, et al, for the DECIMAL, DESTINY and HAMLET investigators: Early decompressive surgery in malignant infarction of the middle cerebral artery: a pooled analysis of three randomized controlled trials. Lancet Neurol 2007;6:315322 .

57 Bousser MG, Welch KMA: Relation between migraine and stroke. Lancet Neurol 2005;4: 533-542.

58 Bousser MG: Patent foramen ovale and migraine: evidence for a link? Headache Curr 2006;3:44-51.

59 Dowson A, Wilmshurst PT, Mullen M, et al: A prospective multicenter, double-blind, placebo-controlled trial to evaluate the efficacy of PFO closure with starflex septal repair implant to prevent refractory migraine headache: the MIST Trial. ACC 55th Annu Sci Session, Atlanta, March 11-14, 2006

60 Dowson A, Mullen MJ, Peatfield R, et al: Migraine intervention with STARFLEX Technology (MIST) Trial. A prospective, multicenter, double-blind, sham-controlled trial to evaluate the effectiveness of $\mathrm{PFO}$ closure with STARFLEX septal repair implant to resolve refractory migraine headache. Circulation 2008;117:1397-1404.

61 Carroll JD: Migraine intervention with STARFLEX technology trial. A controversial trial of migraine and PFO closure. Circulation 2008:117:1358-1360. 